psychologists about how to identify new patterns. Economic, tourist, travel, and migration data will be needed, along with surveys of health providers and informants in the community. A "Maginot Line" approach, based on a few large laboratories, cannot be the centrepiece of this type of free ranging data network, whose objective is to detect perturbances that suggest a change in health status.

A new global rapid response system will be needed to investigate potential new threats to health supported by epidemiological, clinical, and laboratory services. In the modern world national boundaries cannot be an impermeable barrier to such targeted investigations.

Global threats require global thinking and leadership. How we define the problem will determine what we do about it. The time has come to give real priority to the worldwide anticipation, detection, and response to new microbial threats to health. Early detection of the next (already ongoing?) new pandemic will handsomely repay the necessary investment. Global epidemics, including their prevention, recognition, and response, are likely to be an increasing part of the new agenda for international health.

JONATHAN MANN Director

Francois-Xavier Bagnoud Center for Health and Human Rights,

Harvard School of Public Health,

665 Huntington Avenue, Room 1208C,

Boston, MA 02115,

USA

Infectious Diseases,

Mt Auburn Hospital,

330 Mt Auburn Street,

Cambridge, MA 02238,

USA 1 Mann JM, Tarantola D, Netter T, eds. AIDS in the world. Cambridge, MA: Harvard University
Press, 1992.

2 Gibbons A. Where are "new" diseases born? Science 1993;261:680-1.

3 Institute of Medicine. Emerging infections: microbial threats in the United States. Washington, DC: National Academy Press, 1992.

\title{
Poor children in rich countries
}

\section{Markets fail children}

Unicef's annual report for 1993, The Progress of Nations, ${ }^{1}$ makes depressing reading. In some industrialised countries the gains made during the 1970s are slowing or even reversing. The picture varies among countries, but a clear underlying trend is apparent, with differentiation between countries with an Anglo-American culture (the United States, Canada, Britain, Australia, and New Zealand) and those with a continental culture (such as Germany, France, and the Scandinavian and Benelux countries). During the 1980s countries with an Anglo-American culture experienced falls in an index of the social health of children (measured as a combination of infant mortality, government spending on education, the rate of suicide among teenagers, and income distribution) while countries with a continental culture experienced improvements.

The reasons for this difference lie in the differing responses to the slowing of economic growth during the 1980s. These issues are explored in detail in an accompanying volume, Child Neglect in Rich Nations, ${ }^{2}$ in which the author lays the blame firmly at the door of the laissez faire, market based policies introduced by the Anglo-American countries during this period.

These countries, with their tradition of low levels of education and deregulated work places, have pursued policies that favour an expansion of low income jobs in the service sector. In the United States, the average earnings of men fell by $19 \%$ between 1973 and 1987 . Large numbers of women entered the labour market, mostly in low paid part time jobs, so that, despite the number of married women in employment rising by a third over this period, family income rose by only $6 \%$. ${ }^{2}$ Similar phenomena occurred in Britain and Australia. In contrast, continental countries invested in people, with extensive training programmes and policies on minimum wages. As a result, hourly earnings increased in real terms throughout the period in France and Germany. ${ }^{3}$

The two groups of countries also differ in their response to child poverty. Redistribution of income in the AngloAmerican countries has typically been through a shift from progressive to regressive taxes, exemplified by the fall in income tax and rise in value added tax in Britain. This, taken with cuts in benefits, has served to make the poor worse off. In contrast, the continental countries have sought to redistribute income in the opposite way, from the rich to the poor. The consequences of the taxation and benefit systems of different countries are most clearly seen by comparing the percentage of children living in poverty (defined by Unicef as below $40 \%$ of the median family income) in each country. The United States is far above other industrialised countries at $21 \%$. Next come the other Anglo-American countries (Canada, Britain, and Australia) at about $9 \%$. France, Germany, the Netherlands, and Sweden are all below $5 \% .^{2}$

Falling wages have combined with increasing job insecurity to drive people to work much harder. The constant restructuring of industry and the diminishing public sector have meant that no one can be complacent about his or her long term employment. As a result, people in the Anglo-American countries are working much longer hours and taking fewer holidays. ${ }^{2}$ This differs from the situation on the continent, where working long hours is seen as an admission of incompetence, and has greatly affected the time that parents can spend with their children. One study has shown that the total contact time between parents and children in American families has fallen since $1960 .{ }^{4}$ The quality of this contact is also affected as exhausted parents collapse after an increasingly stressful day at work.

Child poverty and reductions in parental contact are much greater when there is only one parent. Again, the increases in family breakdown are much higher in the Anglo-American countries than elsewhere. A quarter of all American children now grow up in a family without a father-a proportion that has doubled within one generation. The implications are both financial and emotional. In Britain and the United States about $40 \%$ of divorced fathers pay no maintenance. Britain's new Child Support Agency is designed to redress this, but it has been more successful in reducing the welfare bill than improving the lot of children. Indeed it appears to have driven children of second families into poverty. The emotional impact of absent fathers is apparent from studies showing that 
these children have much lower educational performances, even after adjustment for differences in income. ${ }^{5}$ Evidence exists that an absent father is an important factor in teenage suicide, ${ }^{6}$ a phenomenon that has increased by $50 \%$ in Britain in the past 20 years.

The differences between the approaches to social policy in the two groups of countries is profound and becoming more so each year. The failure of the British government to ratify the social chapter of the Maastricht Treaty exemplifies Britain's sense of separateness. Unicef's report shows clearly how children have been among the biggest losers. The fundamental problem is that markets simply do not work for children. Continental Europe clearly recognises the future benefits that the state will derive from having a well educated workforce that can compete internationally and invests in future generations instead of regarding children as a private good whose sole function is to provide emotional satisfaction to parents.

Investing in children is simply enlightened self interest. The Institute of Public Policy Research has shown that investment in high quality, affordable child care would yield a direct rate of return to the government of between $5 \%$ and $51 \%$, depending on uptake, and a rate of return to society as a whole (including enhanced earnings and increased tax revenue) of between $24 \%$ and $84 \% .^{7}$ Child Neglect in Rich
Nations points to New Zealand as an example of the social consequences of failing to invest in children, where the dismantling of the welfare state has been associated with rising crime and an increase in the rate of suicides among young people to one of the highest in the industrialised world. Britain and the United States consistently come at the bottom of international comparisons of educational achievement.

The diversity of policies and outcomes in industrialised countries offers clear lessons for policy makers. Unicef's reports are indictments of the laissez faire policies pursued by the Anglo-American countries. Children are our future. If we fail to invest in them we will be the ultimate losers.

MARTIN McKEE Senior lecturer

London School of Hygiene and Tropical Medicine, London WC1E 7HT

1 Unicef. The progress of nations. New York: Unicef, 1993.

2 Hewlett SA. Child neglect in rich nations. New York: Unicef, 1993.

3 Organisation for Economic Cooperation and Development. Historical statistics 1960-89. Paris: OECD, 1991.

4 Fuchs V. Women's quest for economic equality. Cambridge, MA: Harvard University Press, 1988.

5 Fitzgerald Krein S, Beller AH. Educational attainment of children from single-parent families: differences by exposure, gender and race. Demography 1988;25:221-33.

6 Velez CN, Cohen P. Suicidal behavior in a community sample of children: maternal and youth reports. I Am Acad Child Adolesc Psychiatry 1988;27:349-56.

7 Cohen B. Fraser N. Childcare in a modern welfare state: towards a new national policy. London: Institute of Public Policy Research, 1991.
.

\section{Refugee children}

\section{Need coordinated care}

By the end of the century refugees may number 25 million worldwide, half of them children. ${ }^{1}$ The growth of United Nations agencies, better transport, electronic border controls, and evacuations have greatly altered the "world stage" for refugees. Refugee children continue to arrive in countries that are poorly prepared for them. The time has come to formulate policies on the best ways of providing for these vulnerable children. Last month two meetings organised by interested agencies addressed the topic.

Participants agreed that the quality of life for refugee children would be improved if policies were based on the Geneva Convention of 1949 and its additional protocols (1977) as well as the 1989 UN Convention on the Rights of the Child. ${ }^{1}$ When possible, cooperation should continue between the host country and the country of origin. Some European countries already have comprehensive policies to respond to the needs of refugee children, ${ }^{2}$ and other countries should tap into these.

Host countries should have a policy that encourages the reunification of families, and unaccompanied children should never be presumed to be without living relatives; the International Movement of Red Cross and Red Crescent Societies have wide experience of identifying children and tracing family members.

Despite heroic efforts by local people and professionals, children's needs cannot always be met within a country at war, even though this has long been recognised as the ideal. ${ }^{3-5}$ At the meetings refugee doctors from Bosnia described the horrifying state of anarchy and widespread physical, emotional, and sexual abuse of children in their country, the absence of any truly safe havens, and their despair at the lack of a prospect for peace. Angola has one million displaced children and 2000 children in government homes because both parents and the extended family have been killed or imprisoned or are missing. An extended network of foster care has been set up, which includes teams to screen potential foster parents.

Only when children's needs cannot possibly be met in their own country should they be evacuated, and properly secured safe havens are essential for this. Ideally the evacuation of children should be coordinated by the UN High Commission for Refugees, Unicef, and the International Organisation for Migration (an independent intergovernmental agency) according to careful selection criteria. These should be focused on the needs of children as outlined in the UN convention (1989). ${ }^{1}$ If too restrictive they will encourage "unofficial evacuations."

Protocols for evacuation should ensure that children remain with their families and that siblings remain together. Although non-government organisations may have an important role in evacuating children from war zones, some groups lack appropriate selection criteria, registration and assessment procedures, safe transport, or adequate reception facilities. Whenever possible they should work in partnership with the United Nations High Commission for Refugees and Unicef.

Previously, refugee children have not always received optimal management in host countries. Government departments should therefore have clearly defined policies and designated responsibilities, ideally under one coordinating body. The legal status of refugee children, their security and the duration of that security, and their emotional, psychological, medical, and psychiatric needs must all be addressed. In Britain their management will require the coordination of services provided by the Home Office; the Departments of Health, Environment, and Education; the Refugee Council; the UN High Commission for Refugees; Unicef; and the Red Cross. Language and communication facilities should ideally be arranged before their arrival, and children's educational needs and requirements for health care should be addressed 